\title{
Por uma revisão dos estudos curatoriais
}

Lisette Lagnado*

RESUMO: Este artigo procura rastrear a recepção crítica dos primeiros gestos curatoriais no Brasil e propor a necessidade de pesquisas voltadas para a curadoria de arte contemporânea em âmbito acadêmico. Pretende mostrar a importância de um campo específico e complexo, que requer um domínio em várias disciplinas correlatas, abrangendo a história das exposições e das instituições. Num segundo momento, o artigo faz uma revisão da implantação dos programas de especialização inspirados nos curatorial studies, difundidos na Europa nos anos 1990, e conclui que o modelo deveria contemplar uma formação conjunta de artistas e curadores para permitir relações de troca sem reproduzir a separação ocidental entre consciência e sensibilidade, filosofia e poesia.

PALAVRAS-CHAVE: curadoria, exposições, instituições

ABSTRACT: This article intends to track down the critical response to the first curatorial gestures in Brazil and to propose the need for research focused on contemporary art curating in academia. It aims to show the importance of a specific and complex field that requires proficiency in several related disciplines, encompassing the history of exhibitions and institutions. Secondly, the article reviews the implementation of specialization programs taken from the curatorial studies, widespread in Europe in the 1990s, and concludes that the model should include joint training of artists and curators to allow exchanges without reproducing the Western separation of awareness and sensitivity, philosophy and poetry.

KEYWORDS: curatorship, exhibitions, institutions.

\footnotetext{
*Lisette Lagnado é Doutora em Filosofia pela Universidade de São Paulo. Curadora da 27 Bienal de São Paulo (2006), "Desvíos de la deriva" (MNCARS, Madri, 2010) e do $33^{\circ}$ Panorama de Arte Brasileira (MAM-SP, 2013), entre outras mostras. Fundou e coordenou o Projeto Leonilson. Editou a plataforma digital do Programa Hélio Oiticica para o Itaú Cultural. Autora de Cultural Antropophagy. The 24 th Bienal de São Paulo (Afterall, 2015) e O que é uma escola livre? (Oca Lage, Cobogó, 2015). Desde 2014, dirige a Escola de Artes Visuais do Parque Lage (Rio de Janeiro).
} 
Em março de 2008, o mestrado em Artes Visuais da Faculdade Santa Marcelina (FASM) abriu o I Seminário Internacional de Curadoria fazendo uma revisão crítica dos 10 anos da curadoria de Paulo Herkenhoff para a XXIV Bienal de São Paulo (1998). O momento serviu para estudar uma condição contemporânea tão irreversível quanto a globalização da arte: a autoridade curatorial. ${ }^{1}$ À pergunta que norteou o Seminário da FASM (por que dar um lastro acadêmico a uma atividade aparentemente "menor", isto é, "sem qualidade"), sucedeu um debate que deu tônus ao conceito de "contaminação", amplamente reiterado por Herkenhoff, e teve desdobramentos que permitiram examinar o saldo reflexivo da "antropofagia" como "estratégia cultural".

Esse programa semestral de encontros durou apenas quatro anos, mas foi fundamental para abrigar um debate até então mal urdido, em mesas de bar ou entre doutores sem experiência em curadoria. De modo geral no Brasil, a análise estrutural da lógica das exposições não tinha voz dentro de escolas de arte, não representava um campo de estudos, uma disciplina autônoma. Quando mencionados, os argumentos da curadoria eram invariavelmente relegados à esfera do mundano, identificados a uma excrescência da indústria cultural - não que a tese careça de fundamento, nem que tal característica tenha desaparecido, mas imperava o senso comum de que uma exposição é apenas fruto de escolhas "pessoais", arbitrárias ou artificiais. A chave interpretativa então vigente revelava ranços do "tradicional personalismo", que Sérgio Buarque de Holanda denunciou em 1936 como consequência de uma política de privilégios herdada da colonização. Refém desta forma de pensamento, certo discurso habituou-se a imputar relações de interesses ao trabalho curatorial, em vez de ressaltar sua vocação para sedimentar perspectivas institucionais - donde a falta de continuidade em políticas públicas mesmo quando coroadas de resultados positivos. Ainda que a crítica pós-colonial agregue vozes importantes na academia, a tônica personalista se acumula nas filigranas do inconsciente. Hoje, entretanto, que contribuições ainda esperar (ou refutar) de uma formação especializada em curadoria de exposições de arte contemporânea? Em que medida interessa formar turmas de curadores? Um breve histórico se impõe.

\section{Por um campo de estudos curatoriais}

No Brasil, o termo "curadoria" começa a circular no início dos anos 1980 e coincide com a retomada do prestígio internacional da Bienal de São Paulo, após uma década sombria de 
ditadura militar e repressão às liberdades civis. Em 1978, a historiadora Aracy Amaral, envolvida na organização da I Bienal Latino-Americana em São Paulo, que teve curadoria de Juan Acha, teórico da arte de origem peruana, denuncia a posição "servil" do evento em relação à crítica europeia:

Nós, os latino-americanos, ficávamos meio que 'de pingentes', por assim dizer..., não nos olhando muito e vendo-nos sempre como um reflexo nativo em versão subdesenvolvida das correntes europeias ou norte-americanas. Sempre foi assim. Observávamos sempre o que acontecia na Europa, depois nos Estados Unidos, e nunca a nós mesmos, como possíveis pontos de partida ou de revisão crítica das metrópoles. [...] No início da década de 1970, [...] as queixas que sempre ouvíamos na América Latina eram as de que a Bienal de São Paulo, servilmente ligada à crítica europeia, desconhecia a arte latino-americana, traindo sua vocação que deveria ser, por sua própria localização, a de divulgar, estudar e projetar internacionalmente a arte dos países do nosso continente. ${ }^{2}$

Aracy Amaral tenta orientar a bienal a refletir uma condição latino-americana, mas sua hipótese de trabalho não consegue adesão. ${ }^{3} A$ derrota dessa vertente acaba conduzindo o nome de Walter Zanini (1925-2013), que estivera na direção do Museu de Arte Contemporânea da Universidade de São Paulo (MAC-USP) desde sua fundação em 1963, a ser o curador escolhido para as edições de 1981 e 1983.

O regulamento da Bienal de São Paulo, herança de seu fundador, o empresário e colecionador Francisco (Ciccillo) Matarazzo Sobrinho, obedecia a interesses diplomáticos e comerciais de um Brasil desenvolvimentista, peça-chave na política exterior norte-americana dominada pela Guerra Fria. Sob o comando de Zanini - que atuou ainda dentro de um contexto local desprovido de eleições livres - a mostra adota uma montagem por "analogia de linguagens" como artifício para diminuir o impacto das decisões políticas sobre as participações dos países. ${ }^{4}$ É evidente que as nações mais ricas sempre se beneficiaram dos melhores espaços dentro do pavilhão, mas com esta medida o curador consegue aproximar artistas de diversas regiões em um ambiente comum. Em termos históricos, esse gesto inaugura dois momentos importantes para as narrativas críticas: o questionamento das "representações nacionais" e o papel da curadoria na construção de novas bases de interpretação da arte.

A crítica de arte Sheila Leirner assume as duas edições seguintes (1985 e 1987) e leva a Fundação Bienal a integrar os sufixos "pós" e "neo" para acompanhar a agenda contemporânea 
do cenário mundial. As bienais de Leirner exerceram uma função necessária para impedir o envelhecimento precoce de uma instituição nascida sob a égide da modernidade dos anos 1950. Porém, os estudos que mencionam sua curadoria se atém à discussão levantada com a expografia da "Grande Tela" - arquitetura assinada por Haron Cohen e Felipe Crescenti que foi recebida como "corredor da morte", por ter alinhado as pinturas da transvanguarda italiana, do neoexpressionismo alemão e da chamada "pintura matérica" do grupo Casa 7.5 Foi a primeira vez que o meio artístico local invocou limites éticos para a atividade curatorial; a primeira vez também que a curadoria foi identificada a um gesto artístico. Prato cheio para a crítica e a imprensa, que conseguiram sequestrar a visibilidade de um debate maior, perpetuando a doutrina do "cubo branco" e a crença no funcionamento de bienais como extensão da lógica de um museu - um museu ocidental, bem entendido.

Constituída de vários núcleos (incluindo os programas públicos, que variam de publicações, seminários a residências artísticas), a proposta de uma bienal internacional transcende os limites da exposição. Com o passar do tempo, onde ficam os destaques que Leirner conferiu à música (e à vinda de John Cage), à vídeo-arte (com curadoria de Jorge Glusberg) e à performance da dupla Ulay e Marina Abramovic, para ficar apenas com algumas estrelas da Bienal de 1985? Nunca li, por exemplo, um artigo que articulasse três eixos que estavam presentes na 18 BSP: a sala "Expressionismo no Brasil: Heranças e Afinidades" (curadoria de Stella Teixeira de Barros e Ivo Mesquita), Xilogravuras Contemporâneas na Literatura de Cordel e a "Grande Tela".

Não teriam este conjunto de considerações contribuído para os "estudos curatoriais" se tivessem emergido para além de uma análise fragmentada, sala por sala? Segundo Pablo Lafuente, professor visitante na Universidade Federal do Sul da Bahia (UFSB), não se trata de construir uma disciplina: "o importante é ajudar a entender melhor uma exposição; criar entendimento, conhecimento e perspectiva - a disciplina seria um instrumento, não um objetivo." 6

\section{Curadoria: expografia + pesquisa}

A arquitetura de exposições é uma dimensão inextricável do verdadeiro exercício da curadoria. O partido curatorial de Zanini e Leirner ganhou visibilidade por meio da expografia adotada, isto é, de um enunciado espacial. Ambos testemunharam o questionamento de seu 
projeto com argumentos que estabeleceram uma competição entre arte e curadoria, quando a maior cumplicidade existente entre artista e crítico se dá em prol da exposição. A exposição constitui seu território comum, e não de disputa. Nesse sentido, a curadoria transborda as margens reservadas à redação de um texto. Há muitas ferramentas em comum, porém toda curadoria se permite inventar seu próprio método. Trata-se de uma produção outra, com critérios distintos. Por exemplo, até que ponto a teoria estética é válida para definir a qualidade de uma exposição?

Parece-me sintomático observar que as críticas mais agudas e recorrentes se concentraram, inicialmente, na arquitetura expográfica (ou display). Seria o caso de denunciar a carência de um "pensamento espacial", logo no país que protagonizou a arquitetura moderna da mostra "Brazil Builds"? Seria o caso de sugerir que os arquitetos demoraram em se apropriar desse campo de atuação? De fato, sabemos que a relação entre arte e arquitetura é pontuada de disputas quando convidados a trabalhar em colaboração. ${ }^{7}$ Realizadas no imponente Pavilhão Ciccillo Matarazzo, a montagem das bienais de São Paulo se estende sobre mais de trinta mil metros quadrados. Outra hipótese a ser avaliada reside na intimidação que representa trabaIhar dentro de uma obra de Oscar Niemeyer (1907-2012), que assina os edifícios do Parque Ibirapuera, complexo entregue à cidade como marco de seu IV centenário. Hoje em dia, a divulgação do nome do escritório escalado na equipe curatorial costuma acompanhar o anúncio de outros cargos importantes. Ou seja: a valorização do arquiteto de exposições não gerou uma fortuna crítica correspondente, deixando a prática do display descoberta.

Até as bienais de Zanini e Leirner, não se tem registro de grandes alardes em matéria de expografia. Com uma única e ilustre exceção, em 1959, quando Lina Bo Bardi (1914-1992), convidada por Ciccillo a participar da V Bienal, declina do Pavilhão da Bienal e escolhe o pequeno anexo (hoje sede do MAM-SP) para realizar, junto com o dramaturgo Martim Gonçalves, a exposição "Bahia no Ibirapuera". O display criado tinha um caráter ambiental, subvertendo a assepsia do espaço artístico. Nas palavras da crítica e pesquisadora Ana Maria Maia:

\footnotetext{
“Bahia no Ibirapuera” inseriu no histórico do pavilhão e no imaginário daquela V Bienal a experiência vernacular e o despojamento capazes de subverter a 'etiqueta' de uso do espaço expositivo. Na noite de abertura, baianas e capoeiristas abriam rodas para apresentarem-se entre as obras e os convidados. Muitos deles, dentre os quais o presidente Juscelino Kubitschek, comiam acarajé enquanto assistiam à atração. ${ }^{8}$
} 


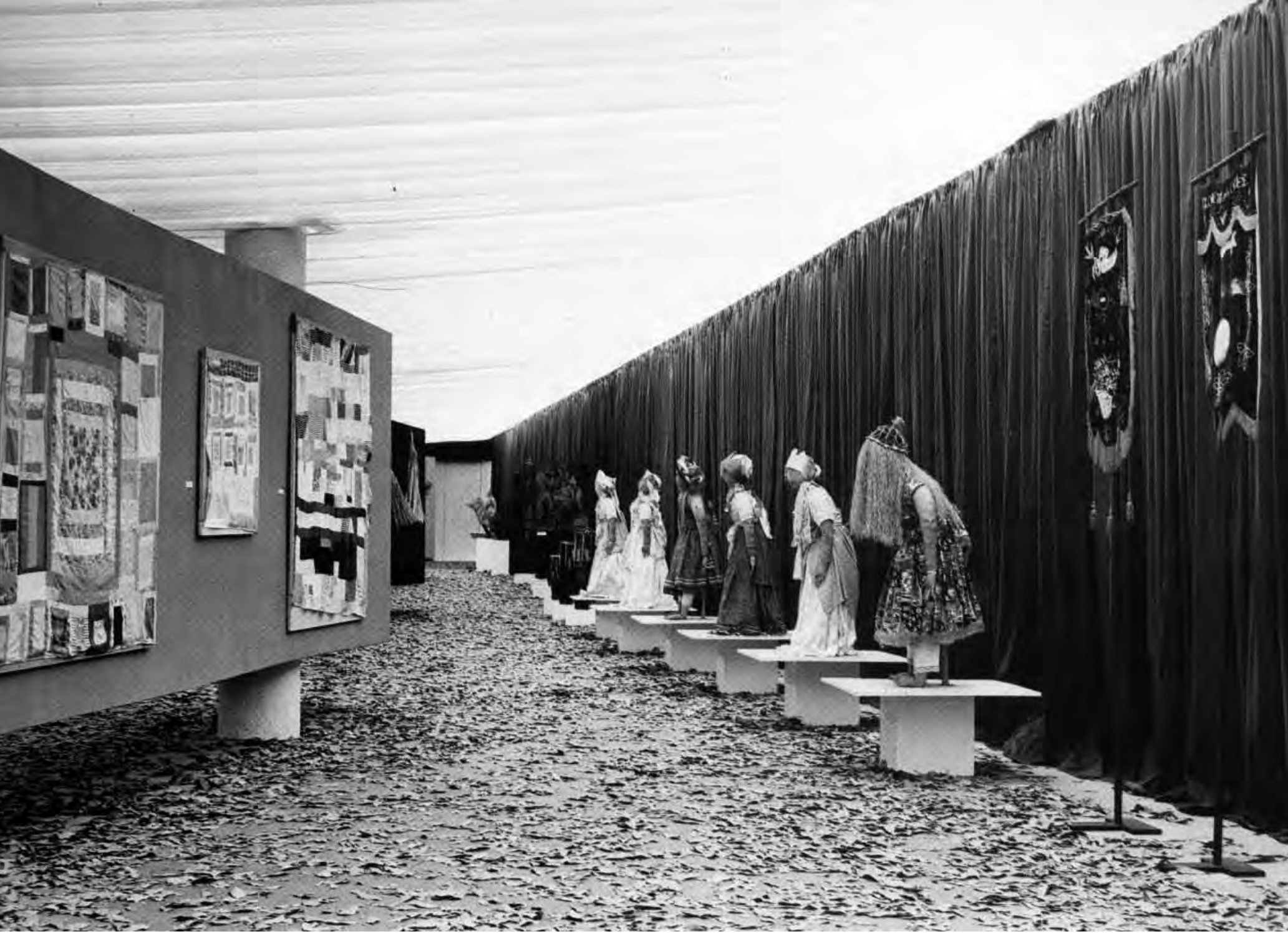

Registro fotográfico da mostra Bahia no lbirapuera

V Bienal de São Paulo, Ibirapuera, 1959

Conceito e projeto expográfico: Lina Bo Bardi

Registro: Instituto Bardi 
Ou seja, vale afirmar que o prestígio da arquitetura moderna brasileira alcançado com uma agenda de grandes mostras internacionais ("Latin American Architecture since 1945", Museum of Modern Art, Nova York) não se traduziu em um pensamento analítico da exposição. Lina Bo Bardi foi singular. Notabilizada internacionalmente com seu consagrado cavalete de vidro, concebido para mostrar as obras da coleção do Museu de Arte de São Paulo (MASP), a marca da arquiteta impregna também o ambiente do Museu de Arte Moderna da Bahia e do SESC Pompéia, exemplos concretos do alerta lançado acerca do impasse do design brasileiro. ${ }^{9}$ Sua contribuição como arquiteta, longe de ser formalista, integra um entendimento maior do fenômeno da cultura e do papel educativo dos museus.

Sabemos que a situação muda de figura nos anos 1980, mas é sem dúvida na XXIV Bienal de São Paulo que o display ganha um estatuto curatorial de alta voltagem ao articular obras de diferentes períodos históricos e origens geográficas. ${ }^{10}$ Esse anacronismo, que o historiador da arte Aby Warburg teria aplaudido, constitui um traço autoral em todas as curadorias que Herkenhoff vem desenvolvendo à frente do Museu de Arte do Rio (MAR).

Até meados dos anos 1990, a ideia de uma curadoria como vocação profissional chegava para uma classe reduzida de viajantes brasileiros que tinham os meios de deslocar-se até o centro da Alemanha a fim de conhecer os epítomes da arte contemporânea. Se a documenta de Kassel (criada em 1955) consagrou-se como a mais prestigiada exposição de arte, é preciso sinalizar que antes da curadoria de Catherine David (documenta X, 1997), esse destino cultural era praticamente incomum nos países do hemisfério sul, ficando reservado a poucos especialistas da arte do Primeiro Mundo. Há uma correlação direta entre a inclusão dos países ditos periféricos em Kassel com o aumento de popularidade da documenta.

No Brasil, embora o termo seja creditado em um ou outro catálogo nos anos 1990, a curadoria estava ainda longe de fornecer um horizonte profissional. É urgente incluir, na história das exposições, o trabalho de Frederico Morais com "Do corpo à terra" (1970) e "Domingos da criação" (1971). ${ }^{11}$ Escrever a trajetória da curadoria no Brasil sem estes dois marcos revela o quanto o meio artístico carece de perspectiva histórica, reiterando apenas as iniciativas do presente, como se não houvesse pensamento curatorial antes da globalização desta atividade.

Quanto ao debate, o nível intelectual ainda oscila entre juízos estéticos formalistas e uma falta total de ousadia (ou autoria). Ao levantar, por exemplo, a ausência de um artista X na lista dos 


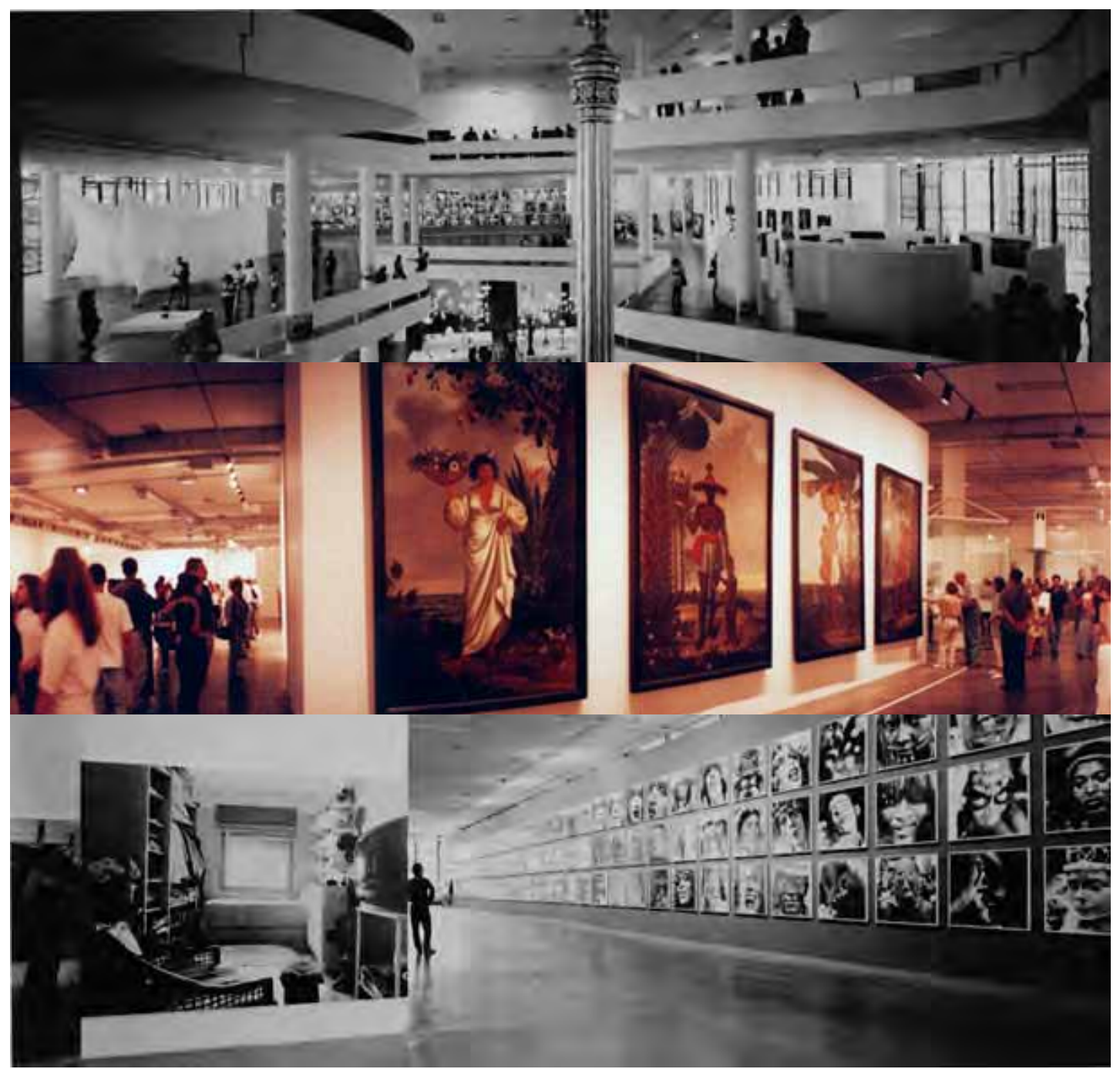

Registros fotográficos da XXIV Bienal de São Paulo, lbirapuera, 1998

Curadoria: Paulo Herkenhoff / Projeto expográfico: Paulo Mendes da Rocha

1. Vista geral do Pavilhão

2. Obras de Albert Eckhout no Núcleo Histórico

3. Obra de Arthur Omar, da série Antropologia da face gloriosa - A grande muralha, 1973-1998 Registro: Gal Oppido 
participantes, ou a escolha de uma obra Y, a discussão escamoteia uma série de considerações, tais como o orçamento da mostra ou as qualidades físicas do edifício, para citar apenas duas condições básicas de produção que exercem uma influência capaz de, muitas vezes, comprometer a realização de um projeto expositivo.

Na realidade, a reputação de um (a) curador (a) se deve muito mais à multiplicação de mostras de arte contemporânea (sobretudo grandes exposições temporárias, como as bienais) que às mostras de cunho histórico. ${ }^{12} \mathrm{O}$ acompanhamento sistemático da produção contemporânea e a troca contínua com artistas em atividade, até mesmo em processo de formação, constitui o ponto divisor entre a formação do crítico de arte e a formação do curador. Enquanto o primeiro analisa objetos de arte, o segundo consegue trabalhar a partir de esboços, projetos ainda não realizados. Por conta dessa característica (uma capacidade de dialogar com o artista no processo de confecção de uma peça inédita), a figura do curador vigorou, em alguns momentos da história, como um sujeito à margem de uma consistência crítica e mais próximo da figura de um "produtor".

Ora, a curadoria é um enunciado ancorado em uma ramificação de empenhos de diversas ordens: artísticas, econômicas, sociais, éticas e políticas. Se uma exposição de grande porte pretende difundir o legado de Lina Bo Bardi, presume-se que a instituição-sede entrará em contato com os respectivos herdeiros ou uma fundação que porta seu nome, a fim de iniciar uma pesquisa e solicitar eventuais empréstimos. No Brasil, pedir obras e documentos para preparar uma exposição é um expediente que acelerou a constituição de acervos (ainda que privados), dada a ausência de uma vigorosa política pública de preservação. Foi o caso do Projeto Leonilson, que surge em 1995, graças à iniciativa de amigos e familiares do artista, para sistematizar sua produção e conseguir, simultaneamente, fazer frente a demandas de divulgação e exibição.

Portanto, o escopo de competências básicas atribuídas à curadoria deriva das metodologias de pesquisa: investigar acervos públicos e privados, conhecer a história da instituição-sede (esse panorama pode implicar desdobramentos de cunho antropológico e social do bairro em que está localizado, da cidade e da população local, da arquitetura do prédio etc.), saber elaborar uma lista com fichas técnicas padronizadas dentro de critérios museológicos, localizar obras raras ou menos conhecidas, prever substituições em caso de impossibilidade de empréstimo, atender assessores de imprensa e outras tantas demandas. Não por acaso, as 
escolas de comunicação e jornalismo têm fornecido uma formação alternativa ao jovem curador brasileiro e em países ainda sem currículo específico para esse profissional.

O aparato expositivo considera etapas preliminares referentes a uma pré-produção (conceito, pesquisa, localização de obras-chave, estudo da circulação no espaço) e uma pós-produção (programação e sinalização visual, textos de parede, educativo e editorial). Na falta de um departamento de pesquisa, a curadoria pode ser solicitada a fornecer todas as informações biográficas dos artistas convidados e acompanhar as peças gráficas que serão produzidas (folheto, cartaz ou catálogo). São poucos os profissionais que entendem que a responsabilidade da curadoria continua depois da inauguração: o acompanhamento das ações educativas confere uma aura inconfundível às visitas públicas. Mas a lista de tarefas traz também variações em virtude de cada orçamento. É comum ser solicitado a fazer a revisão do conteúdo impresso e auxiliar na divulgação. Quanto mais precária for a instituição-sede, maior será o grau de compromisso e a complexidade de demandas que recaem sobre o chamado "curador independente" (leia-se: não vinculado à instituição). É importante que se saiba, contudo, que a figura do curador funciona como tampão de proteção entre artista e instituição, cabendo-lhe uma defesa que muitas vezes esbarra em responsabilidades ambíguas - donde a valorização de qualidades diplomáticas (cordialidade, prudência, discrição etc.).

Gostaria, contudo, de trazer um diferencial que mereceria uma reflexão a parte: no Brasil, como poucas instituições têm um corpo de curadoria, o nome do curador convidado consta na ficha técnica das exposições realizadas em museus. O Museu de Arte Moderna de São Paulo (MAM-SP), por exemplo, menciona o nome do curador de exposições monográficas (de Guignard a Rivane Neuenschwander) ou coletivas, ao passo que os créditos de parede de uma exposição no MNCARS ou Stedelijk, são, em sua maioria, assinados pela instituição, independente do curador organizar mostras com nomes consagrados (seja Mike Kelley, Alejandra Riera ou Otobong Ntkanga).

\section{Contra os estudos curatoriais}

No cenário europeu, a queda do Muro de Berlim em 1989 reforçou a necessidade de tecer leituras cruzadas entre o contexto político e a produção artística. Em 1996 inaugura a Manifesta, bienal europeia de arte contemporânea, com o compromisso de fomentar intercâmbios culturais depois da reunificação. Dentro da realidade latino-americano, as ditaduras já haviam feito 
a "lição de casa" nesse sentido - com exceção do Brasil. Uma breve cronologia ideológica permite localizar questões referentes às transformações da esfera pública (Jürgen Habermas para a democracia liberal europeia, Ernesto Laclau no que tange à promessa populista dos países latino-americanos) e, mais precisamente, à urgência de formar pensadores aptos a articular cultura, exposições e instituições. ${ }^{13}$

É importante sinalizar que artistas como Dominique Gonzalez-Foerster compreenderam desde os anos 1990 sua contribuição no sentido de "produzir" (conceber e realizar) exposições no lugar de objetos. Phillipe Parreno, seu colega de turma na École du Magasin, em Grenoble, justifica dizendo que a exposição é um meio, "a format, just like a novel or a film, or a piece of philosophical writing".14

À guisa de bibliografia, a editora inglesa Afterall vem publicando uma coleção voltada para a "História das Exposições", dedicada a "mostras de arte contemporânea que, desde a primeira documenta de Kassel, na Alemanha, em 1955, deram forma à experiência da arte e ao modo como é feita e discutida". Os volumes disponíveis abrangem os seguintes títulos: "Op Losse Schroeven" e "When Attitudes Become Form" (1969), as mostras com números de Lucy Lippard (1969-74), a $3^{a}$ Bienal de Havana (1989), "Magiciens de la Terre" (1989), "Culture in Action" (1993) e a 24ª Bienal de São Paulo (1998).

As linhas introdutórias do artigo "Mapping international exhibitions" não deixam dúvidas quanto à era da 'bienalização' da arte:

Há uma importante questão política na localização de uma exposição. No caso especial de exposições internacionais estabelecidas como a Bienal de Veneza ou a Documenta, ambas de grande escala -o lugar onde acontecem determina tanto quem será incluído, participante e espectador, como sua tomada de posição e leitura. Por definição, a localização de uma exposição internacional constrói um mapa do mundo a partir tanto da perspectiva da cidade como do país que a patrocina, ressaltando qualquer noção de igualdade de nações. ${ }^{15}$ No Brasil, embora fóruns reunindo jovens curadores tenham se multiplicado, a massa crítica produzida continua insuficiente para historicizar exposições. ${ }^{16}$ Mas antes mesmo da regulação de um programa de estudos curatoriais, assegurar uma parceria entre escolas de arte e acervos e coleções poderia garantir um campo para fomentar novas pesquisas. A trajetória da profissionalização do curador, iniciada com a École du Magasin (Grenoble, 1982), conheceu picos de euforia a 


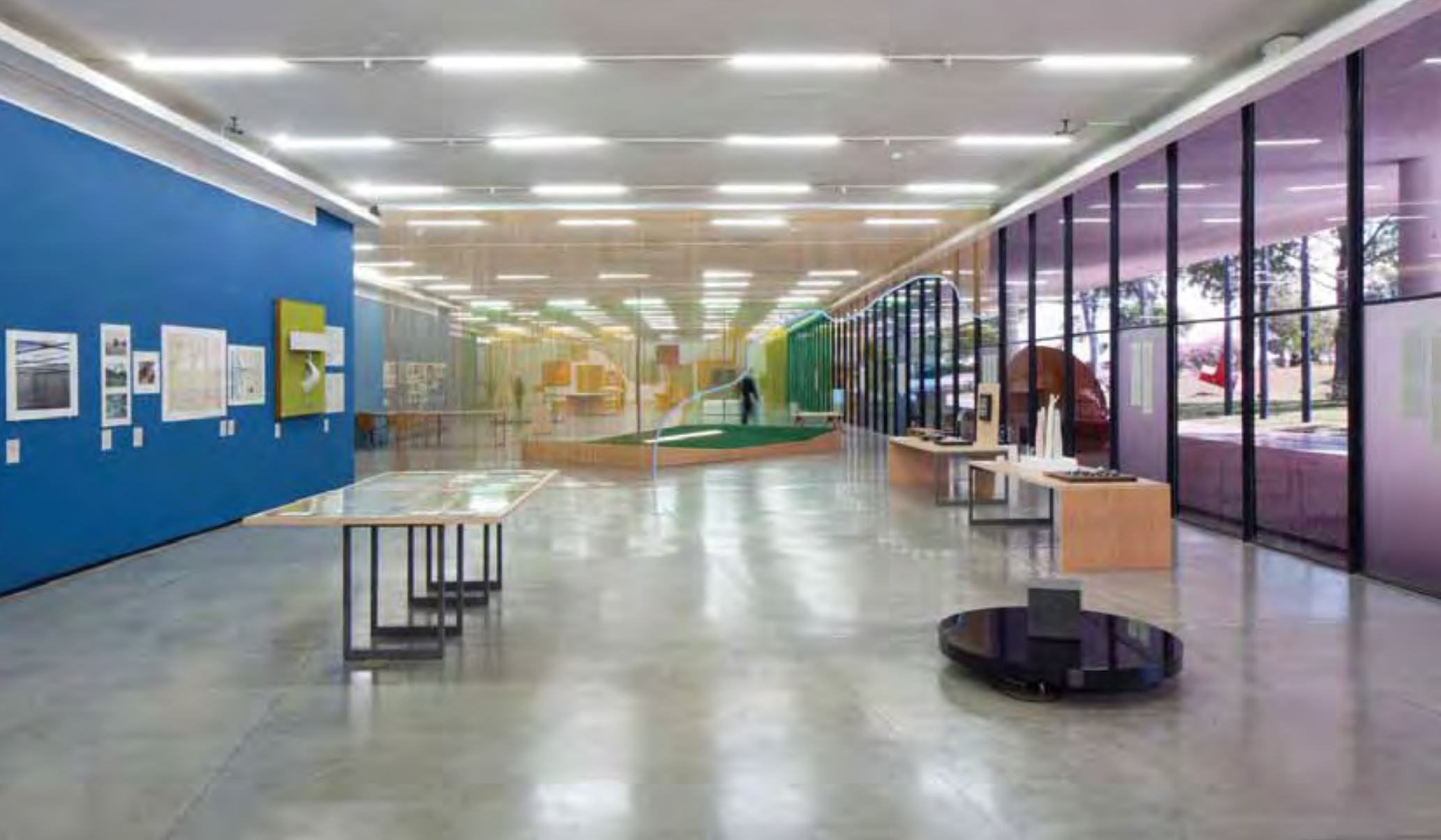

Registros fotográficos do 330 Panorama da Arte Brasileira

P33 Formas Únicas da Continuidade no Espaço, MAM-SP, 2013 Curadoria: Lisette Lagnado / Projeto expográfico: Alvaro Razuk Registro: Ricardo Amado 
partir de 1992 com o programa do Royal College of Art de Londres, seguido em 1994 pelo de Apple arts centre em Amsterdã, entre diversos outros.

Se, por um lado, é necessário introduzir um tônus histórico-teórico às práticas curatoriais, estabelecendo uma diferenciação entre as categorias estéticas que regem a crítica de arte e os critérios que balizam uma curadoria, verifica-se, por outro lado, que a formação de curadores coloca em risco um de seus requisitos mais valiosos com a implantação dos Curatorial Studies (termo anglo-saxão para os "estudos curatoriais"): a convivência entre jovens artistas e seus futuros interlocutores, envolvidos no mesmo processo de aprendizagem e trocas, dispostos a escrever a respeito de suas primeiras experiências expositivas ou lançar proposições coletivas. ${ }^{17}$ Em outras palavras, embora seja necessário entender a especificidade do trabalho curatorial, não se pode continuar sustentando uma separação entre disciplinas teóricas, reservadas à formação de curadores, e disciplinas práticas para os artistas. As escolas de arte perpetuam uma fronteira entre teoria e prática, como se ao artista apenas coubessem aptidões técnicas, e ao curador a responsabilidade de elaborar o trabalho de reflexão.

Ora, a história mostra que o diálogo geracional tem uma forte incidência sobre a evolução do gosto, influindo, portanto na sua capacidade de criar formações sociais de solidariedade que irão constituir um novo horizonte institucional.

A ideia de uma formação especializada que separa o jovem artista do jovem curador reproduz a separação ocidental entre poesia e filosofia. Não seria mais estimulante imaginar um curador desenvolvendo seu poder de olhar e escuta perante uma geração de artistas, com quem estabelecerá novos patamares para uma percepção e um juízo estético? A vocação de um crítico de arte não deveria permitir uma das possibilidades de realização de um artista-escritor?

Gostaria de pensar a curadoria como um território que aproxima poesia e filosofia. Giorgio Agamben explica que nenhuma delas "cai do céu"; e que de ambas emana uma autoconsciência. ${ }^{18}$ Desde a tradição platonicista, "a separação entre poesia e filosofia, entre palavra poética e palavra pensante" é um assunto caro à cultura ocidental. O problema de possessão do objeto de conhecimento é um problema de linguagem (certamente de gozo, também). Aplicando esse raciocínio para entender como se estrutura uma exposição, chega-se a uma bela encruzilhada: a tarefa da curadoria se vale simultaneamente da liberdade do gesto artístico e de um projeto crítico, pois não há dúvida que a curadoria se configura como tentativa de criar espaços de leitura. 
Temos a obrigação de explicitar aos jovens entusiastas que ingressam nos programas de "artes visuais" que a curadoria já não é a mesma profissão "independente" que Harald Szeemann (1933-2005) legou ao mundo da arte; que a responsabilidade do fund raising hoje consta em muitos contratos internacionais; que a censura dominou uma atividade que parecia livre até dos entraves acadêmicos. Ignoradas (de forma consciente ou não) pela crítica especializada que visita exposições, as mazelas cotidianas das negociações curatoriais para conseguir erguer um conjunto coeso de obras não deveriam permanecer na zona confidencial do não dito, uma vez que carregam a potência de iluminar a porção perversa da engrenagem do circuito da arte.

A esfera do silêncio (ou segredo profissional) exige um balanço entre argumentos corporativos versus sensacionalismo, fragilidade versus transparência das instituições públicas. Não é tarefa fácil discernir quais informações têm valor e função para integrar a análise de uma exposição, a ponto de transformar a percepção que teremos dela, podendo até mesmo mudar o sentido das obras. Um dos tópicos mais controversos da atualidade sem dúvida reside no problema da censura institucional, ameaçando a liberdade de expressão de curadores cada vez mais acuados por um departamento jurídico que passou da defesa para a ofensiva. ${ }^{19}$

Em 2006, a pesquisa de Chin-tao $\mathrm{Wu}^{20}$ afirmou claramente que, com o processo mundial de privatização da cultura, a formação em curadoria está incorporando requisitos em administração empresarial. O que fazer diante da tenebrosa ameaça de deslocar os "estudos curatoriais" para o campo de gestão de eventos e "empreendedorismo"? Este desafio, deixo à próxima geração.

\section{Notas}

1 Entre 2008 e 2011, organizei oito seminários (abertos ao público) voltados para diversas modalidades de práticas curatoriais, trazendo os seguintes convidados para a Faculdade Santa Marcelina: Paulo Herkenhoff, Adriano Pedrosa, Ricardo Basbaum, Denise Mattar, Ferrán Barenblit, Rodrigo Moura com Maria Inés Rodrigues, e, por último, Pablo Lafuente. Uma das sessões contou com a projeção do filme $O$ que vocês fazem quando fazem ou esperam fazer curadoria?, da videoinstalação com o mesmo título de Pablo Lobato e Yuri Firmeza. Sob orientação minha e da Prof ${ }^{a}$ Mirtes Marins de Oliveira, esses estudos de exposição funcionaram na Escola São Paulo de 2012 a 2013.

2 AMARAL, Aracy. Arte e meio artístico: entre a feijoada e o x-burguer (1961-1981). São Paulo: Nobel, 1983, pp. 297 e 299.

3 Cf. documento doado por A. Amaral ao Arquivo da Fundação Bienal. 
4 LAGNADO, Lisette; LAFUENTE, Pablo (ed.). Cultural Anthropophagy. The 24th Bienal de São Paulo 1998. Londres: Afterall Books e Center for Cultural Studies, Bard College, Exhibition Histories, 2015.

5 18 Bienal de São Paulo, "O Homem e a Vida". 4/10 a 15/12/1985. "Em três corredores de 100 metros de extensão por 6 metros de largura e 5 metros de altura, Leirner enfileirou dezenas de quadros, com uma distância de apenas 30 centímetros entre cada um, a compor o que chamou de a 'Grande Tela'.' Cf. http://entretenimento.uol.com.br/arte/bienal/1985/

6 Em correspondência com a autora, 10/12/2015. Pablo Lafuente foi co-curador da $31^{\text {a }}$ Bienal de São Paulo, editor da coleção Exhibition Histories (Afterall) e professor na Central Saint Martins, University of the Arts London.

7 Frank Gehry influenciou uma geração de artistas e arquitetos em Los Angeles. Houve uma inflação de projetos para o espaço público a partir dos anos 1980 com a arquitetura pós-moderna, sendo Hal Foster seu crítico mais interessante. Entre as colaborações notáveis, cabe lembrar-se de Herzog \& de Meuron com Thomas Ruff (Eberswalde Library, Alemanha) e a instalação de Pipilloti Rist para a Embaixada Suiça em Berlim.

8 Cf. MAIA, Ana Maria. Museu de Cera, Pavilhão da Marquise, Pavilhão Bahia, Museu de Arte Moderna de São Paulo. In: $33^{\circ}$ Panorama da Arte Brasileira. P33. Formas únicas da continuidade no espaço. Catálogo, São Paulo, 5 de outubro a 15 de dezembro de 2013, p. 31. 9 Cf. BO BARDI, Lina. Tempos de grossura: o design no impasse. São Paulo: Instituto Lina Bo e P. M. Bardi, 1994.

10 Paulo Mendes da Rocha foi o arquiteto responsável pela XXIV BSP. Em São Paulo, a expografia como forma de pensamento vem ganhando destaque com diversos escritórios: Álvaro Razuk, Vinícius de Andrade e Marcelo Morettin (Andrade Morettin), Álvaro Puntoni e João Sodré (gruposp), Angelo Bucci (spbr), Marta Bogéa, Martin Corullon e Gustavo Cedroni (Metro), Pedro Mendes da Rocha (Arquitetos Associados), Rodrigo Cerviño Lopez e Fernando Falcon (Tacoa), Estúdio Risco, entre outros. Em Inhotim (MG), os Arquitetos Associados têm assinado vários pavilhões.

11 Cf. https://www.ufmg.br/revistaufmg/downloads/20/18-entrevista_fredrico_morais.pdf

12 Uma das primeiras obras de referência a se tornar clássica no Brasil foi: Thinking about Exhibitions (ed. Reesa Greenberg, Bruce W. Ferguson e Sandy Nairne). Londres e Nova York: Routledge, 1996. O cenário mudou e uma ampla bibliografia passou a ser traduzida e circular em âmbito acadêmico. Nos últimos dez anos, a multiplicação de programas independentes para novos curadores atraiu jovens com talentos diferenciados: Marcelo Campos, Marisa Flórido, Marcio Harum, Cristiana Tejo, Marisa Mokarzel, Daniela Labra, Fernando Oliva, Marta Mestre, Fernanda Lopes, Julia Rebouças, Luisa Duarte, Clarissa Diniz, Ana Maria Maia,,Daniela Castro, Cauê Alves, Felipe Scovino, Bernardo Mosqueira e Bernardo de Souza, entre outros.

13 O Centro de Pesquisa e Formação do SESC São Paulo acolheu este ano investigações no campo dos Estudos das Exposições, com orientação das Prof ${ }^{a}$ Mirtes Marins de Oliveira e Ana Maria Maia. Este programa articula a análise de exposições atuais e históricas, demonstrando a inserção de projetos ideológicos na materialidade das mostras, e a idealização ou enquadramento dos visitantes em modelos pré-determinados. Os cursos de curta duração (vinte horas) têm recebido profissionais interessados nessa linha de fundamentação como bagagem teórica necessária na formação do curador de arte e cultura contemporâneas.

14 A coleção "Exhibition Histories" é um projeto de pesquisa abrigado na Central Saint Martins e conta com o apoio do Center for Curatorial Studies, Bard College (EUA). O professor de História da Arte Vinicius P. Spricigo vem desenvolvido um trabalho similar na UNIFESP, porém dentro da área de Arqueologia das Exposições.

15 Tradução livre da autora para a presente edição. Parece, entretanto ter havido um erro de impressão: onde lê-se "underlining", na última frase, faria mais sentido se fosse "undermining." Na impossibilidade de verificar a veracidade dessa inferência, a verbo "underline" foi mantido. "There is an important politics in the locality of an exhibition. Where an exhibition is staged, particularly one of the perennial large-scale international exhibitions like the Venice Biennial or Documenta, determines who is included, both as participants and viewers, as well as how that exhibition is positioned and read. By definition, the location of an international exhibition constructs 
a map of the world from the perspective of both the city and the country that sponsor it, underlining any notion of an equality of nations." Ensaio de Bruce W. Ferguson, Reesa Greenberg e Sandy Nairne, publicado em 1993. Reimpresso em: VANDERLINDEN, Barbara; FILIPOVIC, Elena (ed.). The Manifesta Decade. Debates on Contemporary Art Exhibitions and Biennials in Post-Wall Europe. Cambridge: Roomade e MIT Press, 2005, p. 47.

16 Os estudos em curadoria no Brasil permanecem pouco explorados, embora a demanda seja imensa, conforme verificado nos cursos de curta duração. Além de uma Graduação em Arte: História, Crítica e Curadoria, a PUC-SP tem uma Especialização em Arte: Crítica e Curadoria. O SENAC também oferece uma Especialização em Arte e Curadoria. No portal do Ministério da Educação (MEC), dentro dos programas strictu sensu existentes, Artes (ou História da Arte) aparece como área, não aparecendo a Curadoria como subárea, proposta de concentração ou de linha de pesquisa. O Centro Universitário Belas Artes de São Paulo possui a opção Museologia, Colecionismo e Curadoria. Já os cursos de gestão para o mercado de arte têm se tornado um nicho (a FGV abriu esta opção em 2015), com aulas de teoria da arte visando atender colecionadores, executivos, empresários e funcionários de galerias.

17 Para maiores informações, recomendo aqui o trabalho feito pela crítica e curadora argentina Inés Katzenstein na Universidad Torcuato Di Tella. Cf. http://www.utdt.edu/ver_contenido.php?id_contenido=3519\&id_item_menu=7139

18 AGAMBEN, Giorgio. Stanze. Parole et fantasme dans la culture occidentale. Traduzido do italiano por Yves Hersant. Paris: Payot \& Rivages, 1994

19 A exposição “The Beast is the Sovereign" (coprodução do Museu d'Art Contemporani de Barcelona, MACBA e do Württembergischer Kunstverein Stuttgart, WKV), é o mais recente caso a ocupar a mídia especializada. A celeuma teria sido uma escultura de Ines Doujak, Not Dressed for Conquering/ HC 04 Transport. Acarretou em março de 2015 a demissão dos curadores do MACBA, Valentín Roma e Paul B. Preciado, por "deslealdade à instituição". As consequências ainda se fazem sentir com a renúncia de três membros do Conselho do CIMAM, em novembro de 2015. Para maiores informações, há vários links na internet. http://conversations.e-flux.com/t/ the-socialist-and-the-sovereign-censored-show-opens-at-wurttembergischer-kunstverein/2696

20WU, Chin-tao. Privatização da cultura: a intervenção corporativa nas artes desde os anos 1980. Tradução de Paulo Cezar Castanheira. São Paulo: Boitempo, 2006.

\section{Referências}

AMARAL, Aracy. Arte e meio artístico: entre a feijoada e o x-burguer (1961-1981). São Paulo: Nobel, 1983.

BO BARDI, Lina. Tempos de grossura: o design no impasse. São Paulo: Instituto Lina Bo e P. M. Bardi, 1994.

GREENBERG, Reesa; FERGUSON, Bruce W.; NAIRNE, Sandy (Ed.). Thinking about Exhibitions. Londres e Nova York: Routledge, 1996.

LAGNADO, Lisette; LAFUENTE, Pablo (Ed.). Cultural Anthropophagy. The 24th Bienal de São Paulo 1998. Londres: Afterall Books e Center for Cultural Studies, Bard College, Exhibition Histories, 2015)

MAIA, Ana Maria. Museu de Cera, Pavilhão da Marquise, Pavilhão Bahia, Museu de Arte Moderna de São Paulo. In: $33^{\circ}$ Panorama da Arte Brasileira. P33. Formas únicas da continuidade no espaço. Catálogo, São Paulo, 5 de outubro a 15 de dezembro de 2013.

STEEDS, Lucy. Exibition. Documents of Contemporary Art. Londres, Cambridge Mass.: Whitechapel Gallery, the MIT Press, 2014.

VANDERLINDEN, Barbara; FILIPOVIC, Elena (Ed.). The Manifesta Decade. Debates on Contemporary Art Exhibitions and Biennials in Post-Wall Europe. Cambridge: Roomade e MIT Press, 2005.

WU, Chin-tao. Privatização da cultura: a intervenção corporativa nas artes desde os anos 1980. Tradução de Paulo Cezar Castanheira. São Paulo: Boitempo, 2006. 